\title{
Brunelliaceae endémicas del Perú
}

\author{
Blanca León ${ }^{1,2}$
}

${ }^{1}$ Museo de Historia Natural,
Av. Arenales 1256, Aptdo.
14-0434, Lima 14, Perú
${ }^{2}$ Plant Resources Center,
University of Texas at
Austin, Austin TX 78712
EE.UU.
blanca.leon@mail.utexas.edu

\section{Resumen}

La familia Brunelliaceae es reconocida en el Perú con 12 especies en el género Brunellia (Brako \& Zarucchi, 1993), todas ellas especies arbóreas. Estos taxones endémicos ocupan principalmente la región Bosques Muy Húmedos Montanos, entre los 1500 y $3000 \mathrm{~m}$ de altitud. En el presente trabajo se reconocen siete especies endémicas, asignándose categorías de amenaza de la UICN a tres de ellas. Dos especies endémicas han sido registradas dentro del Sistema Nacional de Áreas Naturales Protegidas por el Estado.

Palabras claves: Brunelliaceae, Brunellia, Perú, endemismo, plantas endémicas.

\section{Abstract}

The Brunelliaceae are represented in Peru by 12 species in the genus Brunellia (Brako \& Zarucchi, 1993), all of them trees. Endemic Brunelliaceae are found in the Very Humid Montane Forests region, between 1500 and 3000 m elevation. Here we recognize seven endemic species, and we applied IUCN categories and criteria to three of them. Two endemic species have been recorded to date from the Peruvian parks system.

Keywords: Brunelliaceae, Brunellia, Peru, endemism, endemic plants.

\section{Brunellia briquetii Baehni}

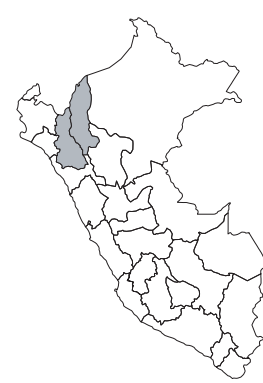

Publicación: Field Mus. Nat. Hist., Bot. Ser. 13(2/3): 1040. 1938.

Colección tipo: A. Mathews s.n.

Herbarios: BM, G, K.

Nombre común: Desconocido.

Registro departamental: AM, CA.

Regiones Ecológicas: BMHM; altitud desconocida.

SINANPE: Sin registro.

Herbarios peruanos: Ninguno.

Observaciones: Árbol conocido aparentemente de dos localidades en el norte del país. No ha sido posible evaluarlo, ni asignarle una categoría.

\section{Brunellia brunnea J.F. Macbr.}

Publicación: Candollea 5: 361. 1934. Colección tipo: A. Weberbauer 6969 Herbarios: B, G, GH, US; MOL!. Nombre común: Desconocido. Registro departamental: CU, SM. Regiones Ecológicas: BMHM; 2100$2200 \mathrm{~m}$.

SINANPE: PNM

Herbarios peruanos: MOL (isotipo).

Observaciones: Árbol conocido aparentemente de poblaciones aisladas en el norte y centro del país. El ejemplar tipo fue recolectado en 1914 de la cuenca del Alto Madre de Dios, en lo que hoy es el límite occidental del Parque Nacional Manu. No ha sido posible evaluarlo, ni asignarle una categoría.

\section{Brunellia cuzcoensis Cuatrec.}

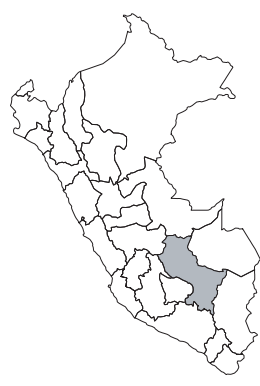

Publicación: Fl. Neotrop. 2: 143-144. 1970.

Colección tipo: C. Vargas C. 13967

Herbarios: US.

Nombre común: Desconocido.

Registro departamental: CU.

Regiones Ecológicas: BPM; $3150 \mathrm{~m}$.

SINANPE: PNM

Herbarios peruanos: Ninguno.

Observaciones: Árbol descrito de una planta recolectada en el lado occidental del Parque Nacional Manu. Esta especie fue recolectada en 1962, de una localidad a mayor altitud que la de la endémica, Brunellia brunnea. Al parecer, registrada también en la cuenca del Mayo, pero no se verificó esa planta. No ha sido posible evaluarlo, ni asignarle una categoría.

\section{Brunellia dichapetaloides J.F. Macbr.}

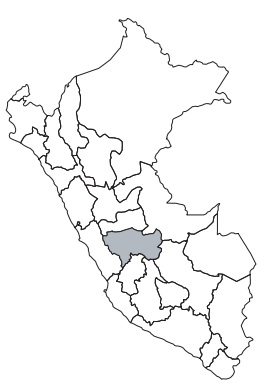

\section{CR, B1ab(iii)}

Publicación: Candollea 5: 361. 1934.

Colección tipo: C.O. Schunke 83

Herbarios: F.

Nombre común: Desconocido.

Registro departamental: JU.

Regiones Ecológicas: BMHM; $1500 \mathrm{~m}$.

SINANPE: Sin registro.

Herbarios peruanos: Ninguno.

Observaciones: Árbol descrito de una planta recolectada en 1929 del valle de Chanchamayo, en la antigua hacienda Schunke, la cual se ubicaba muy cerca de la ciudad de La Merced. Esta parte del valle ha sido extensamente transformada en favor de la actividad agricola y de la expansion urbana. Si bien poco se ha explorado los remanentes de bosque para saber si podrian haber poblaciones de esta especie, se la considera como En peligro Critico dado el tiempo transcurrido desde su ultima recoleccion y el hecho de que su localidad original ha sido destruida. 


\section{Brunellia dulcis J.F. Macbr.}

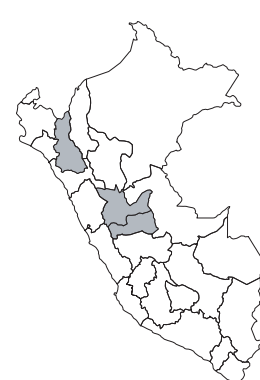

\section{EN, B1ab(iii)}

Publicación: Candollea 5: 362. 1934. Colección tipo: M. Sawada 74

Herbarios: F, G.

Nombre común: Desconocido.

Registro departamental: CA, HU, PA.

Regiones Ecológicas: MA, BMHM; 2000-2230 m.

SINANPE: Sin registro.

Herbarios peruanos: Ninguno.

Observaciones: Árbol conocido aparentemente de varias poblaciones dispersas, en el nor-oriente del país, todas en la cuenca del Marañón. Los bosques de donde se conoce está especie están amenazados por la deforestación.

\section{Brunellia hexasepala Loes.}

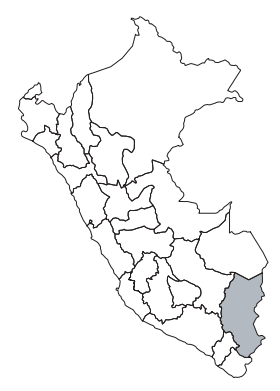

Publicación: Bot. Jahrb. Syst. 37: 531. 1906.

Colección tipo: A. Weberbauer 734

Herbarios: B.

Nombre común: Desconocido.

Registro departamental: PU.

Regiones Ecológicas: BMHM; 2400$3000 \mathrm{~m}$.

SINANPE: Sin registro.

Herbarios peruanos: Ninguno.

Observaciones: Árbol descrito de una planta recolectada en 1902 del sur del país. No ha sido posible evaluarlo, ni asignarle una categoría.

\section{Brunellia weberbaueri Loes.}

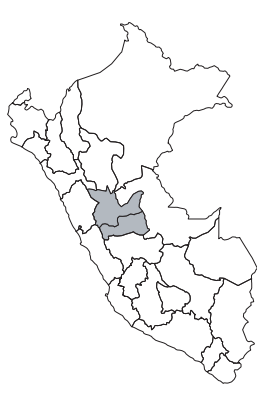

\section{VU, B1a}

Publicación: Bot. Jahrb. Syst. 37: 532. 1906.

Colección tipo: A. Weberbauer 6781

Herbarios: B, F; MOL!.

Nombre común: Desconocido.

Registro departamental: HU, PA.

Regiones Ecológicas: BMHM; 1800$2450 \mathrm{~m}$.

SINANPE: Sin registro.

Herbarios peruanos: MOL (isotipo).

Observaciones: Árbol descrito originalmente de una planta recolectada en 1903, en la cuenca del Monzón; una de las zonas menos herborizadas de la vertiente oriental. El ejemplar que se reconoce hoy como tipo proviene de la cuenca del Pozuzo. Otras poblaciones de esta especie han sido recolectadas también en el centro del país. 